\section{CENTRO DE CIÊNCIA E TECNOLOGIATÊXTIL}

\section{www.2c2t.uminho.pt}

\title{
Chitosan-based blended films for wound dressing applications
}

Joana C. Antunes*, Joana Domingues, M. Teresa P. Amorim, Helena P. Felgueiras Centro de Ciência e Tecnologia Têxtil (2C2T), Universidade do Minho, Portugal *ioana.antunes@2c2t.uminho.pt

\section{Introduction}

Chronic wounds (CW) have numerous entry ways for pathogen invasion and prosperity, which further damages host tissue and hinders tissue remodeling. Essential oils (EOs) exert quick and efficient antimicrobial (AM) action, unlikely to induce bacterial resistance. Cinnamon leaf oil (CLO) is a well-studied EO with strong AM properties. In this work, CLO was added to chitosan (Ch) and polyvinyl alcohol (PVA) solutions. Ch is a natural cationic polysaccharide with antibacterial, anti-inflammatory and regenerative properties. PVA adds flexibility and hydrophilicity to the blend. Ch and PVA (72 KDa, $88 \%$ hydrolysed) films were prepared by solvent casting and phase inversion method (as previously done by the lab). CLO was added to Ch solution shortly before blending. The goal of this work is to provide a first proof of concept that CLO can be dispersed into $\mathrm{Ch}$ and PVA films and show bactericidal effects, opening new perspectives for $\mathrm{CW}$ therapeutics.

\section{Ch/PVA Film Production}

Materials: Ch, Mw $100,000-300,000$ and $9.7 \pm 0.6 \%$ of acetylglucosamine units, and PVA, Mw 72,000 and 88\% hydrolyzed; acetic acid and distilled water as solvents; coagulation bath of sodium sulfate $\left(\mathrm{Na}_{2} \mathrm{SO}_{4}\right)$ and sodium hydroxide $(\mathrm{NaOH})$

Method: Solvent Casting followed by Phase-Inversion
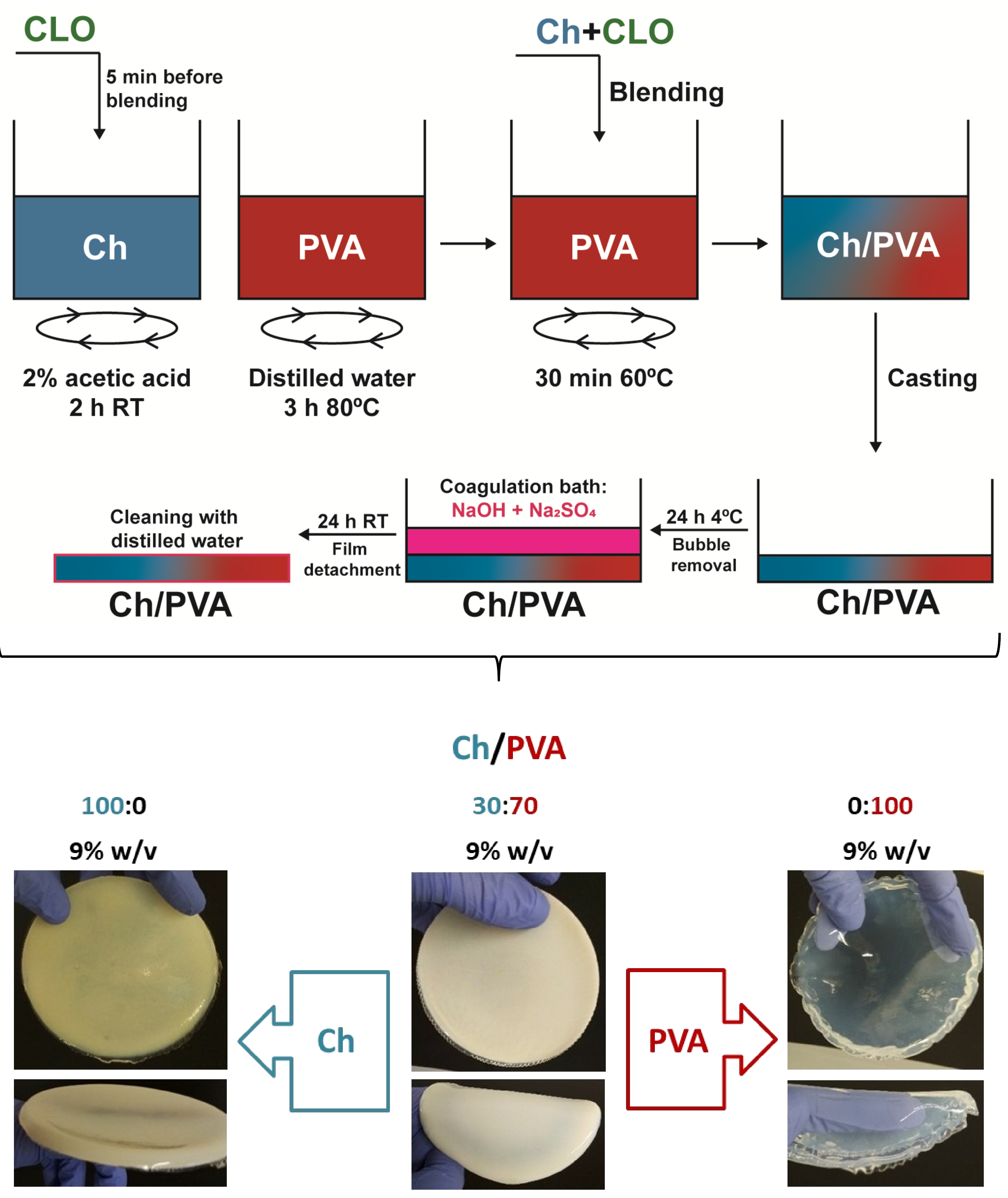

1) Antibacterial action of CLO

\begin{tabular}{ccc}
\hline Antimicrobial Agent & \multicolumn{2}{c}{$\mathrm{MICs}(\mu \mathrm{g} / \mathrm{mL})$} \\
SLO & 26.2 & E. coli \\
\hline & & 19.7
\end{tabular}

2) Fourier-Transformed Infrared Spectroscopy with Attenuated Total Reflectance (ATR-FTIR)
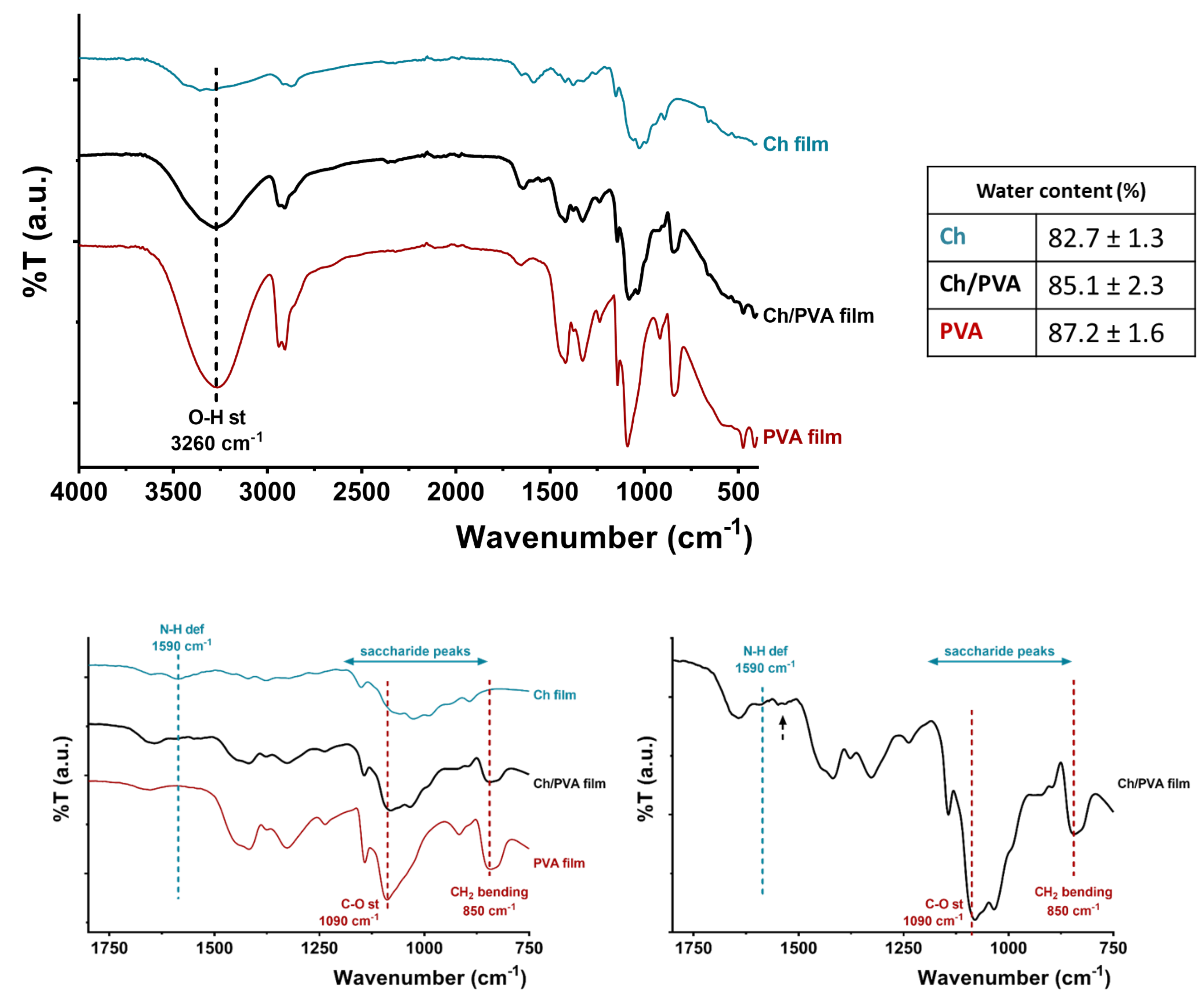

Ch/PVA film:

Peaks of both polymers are present $\_$suggesting $\longrightarrow \quad$ Polymers blend No new peaks are formed $\stackrel{\text { suggesting }}{\longrightarrow}$ Hydrogen bond formation

2) Antibacterial action of built films

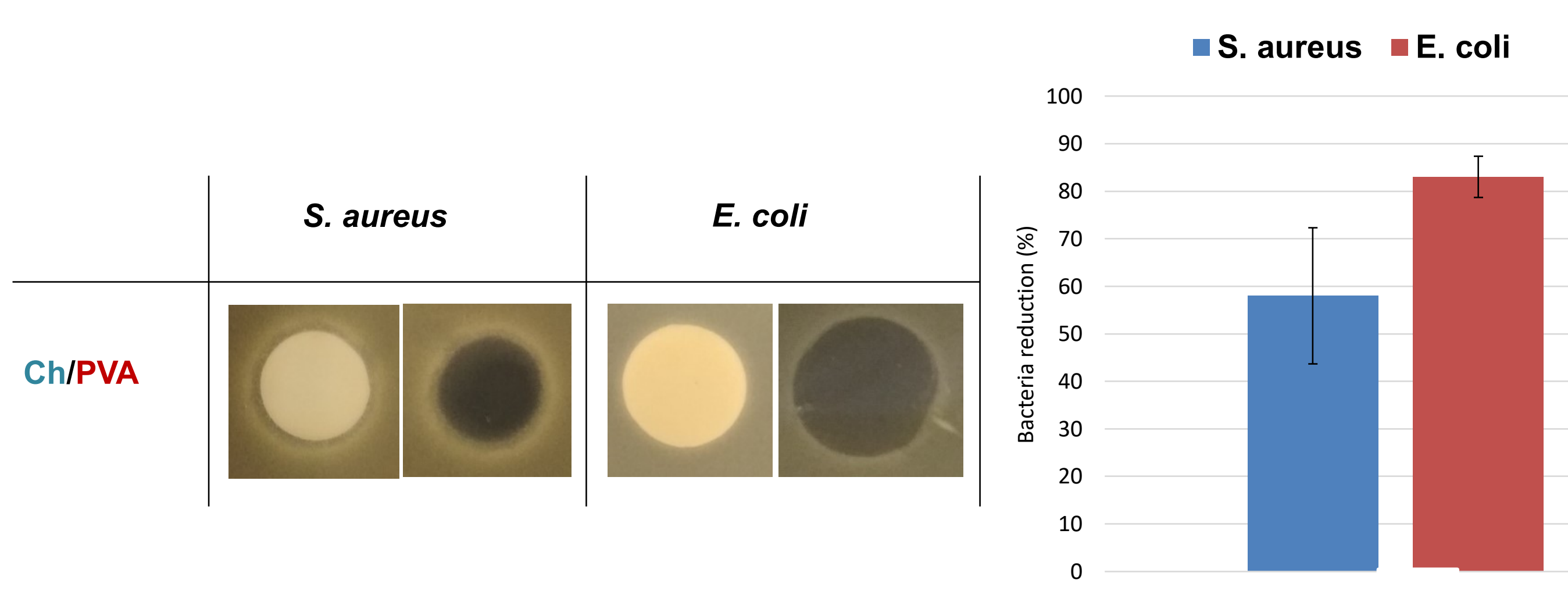

Conclusions: CLO functionalized Ch/PVA films has potential for $\mathrm{CW}$ wound dressing applications.

For more details please refer to DOI: 10.1002/app.48626 